\title{
ASSOCIATIONS BETWEEN CARDIO-METABOLIC ABNORMALITIES AND ADIPOSITY BY GENDER AND POPULATION GROUPS IN SOUTH AFRICA
}

\section{BACKGROUND}

- Overweight and obesity $\rightarrow$ key risk factors for diabetes, hypertension and dyslipidaemia

- Epidemic of overweight and obesity in South Africa $\rightarrow$ contributes to the high and rising burden of these cardio-metabolic diseases

- However, adiposity may be differentially associated with cardiometabolic diseases $\rightarrow$ by gender and ethnicity

\section{AIM}

To determine whether adiposity, calculated by body mass index (BMI), was differentially associated with diabetes, hypertension and hypercholesterolaemia by gender and population groups in the Heart and Stroke Foundation South Africa's screening programme.

\section{METHODS}

Study Population

$\geq 18$-year-old adults

Study Design

\section{Cross-sectiona}

Conducted in 5 out of 9 provinces

Urban and semi-urban areas

\section{Data Collection \\ Clinical}

'Cardiovascular Health Check' questionnaire

Anthropometry, blood pressure (BP)

Biochemical

Point-of-care random blood glucose (RBG),

Cholesterol assessments

Data Analysis

Descriptive statistics

Logistic regressions

\section{DEFINITIONS}

BMI

Hypertension

Diabetes

Hypercholesterolaemia: total cholesterol $\geq 5 \mathrm{mmol} / /$

\section{RESULTS}

Table 1: Distribution of adiposity by gender and population group

\begin{tabular}{|l|c|c|c|c|}
\hline & UNDERWEIGHT & NORMAL WEIGHT & OVERWEIGHT & OBESE \\
\hline MEN (N=2482) & $\mathrm{N}=59$ & $\mathrm{~N}=798$ & $\mathrm{~N}=987$ & $\mathrm{~N}=638$ \\
\hline Age in years, mean \pm SD & $40.7 \pm 18.8$ & $45.0 \pm 17.8$ & $49.1 \pm 15.8$ & $49.1 \pm 14.1$ \\
\hline Prevalence, \% & 2.4 & 32.1 & 39.8 & 25.7 \\
\hline WOMEN (N=5213) & $\mathrm{N}=81$ & $\mathrm{~N}=1322$ & $\mathrm{~N}=1530$ & $\mathrm{~N}=2280$ \\
\hline Age in years, mean \pm SD & $46.8 \pm 22.1$ & $46.2 \pm 18.9$ & $49.6 \pm 16.7$ & $49.3 \pm 14.1$ \\
\hline Prevalence, \% & 1.6 & 25.4 & 29.3 & 43.7 \\
\hline POPULATION GROUP, $\%$ & $\mathrm{~N}=140$ & $\mathrm{~N}=2120$ & $\mathrm{~N}=2517$ & $\mathrm{~N}=2918$ \\
\hline Black $(\mathrm{n}=2761)$ & 1.3 & 23.2 & 28.0 & 47.5 \\
\hline Coloured $(n=1773)$ & 1.5 & 22.4 & 33.1 & 43.0 \\
\hline White $(n=1592)$ & 2.1 & 34.2 & 36.1 & 27.6 \\
\hline Indian $(\mathrm{n}=1238)$ & 3.0 & 34.7 & 36.7 & 25.6 \\
\hline
\end{tabular}

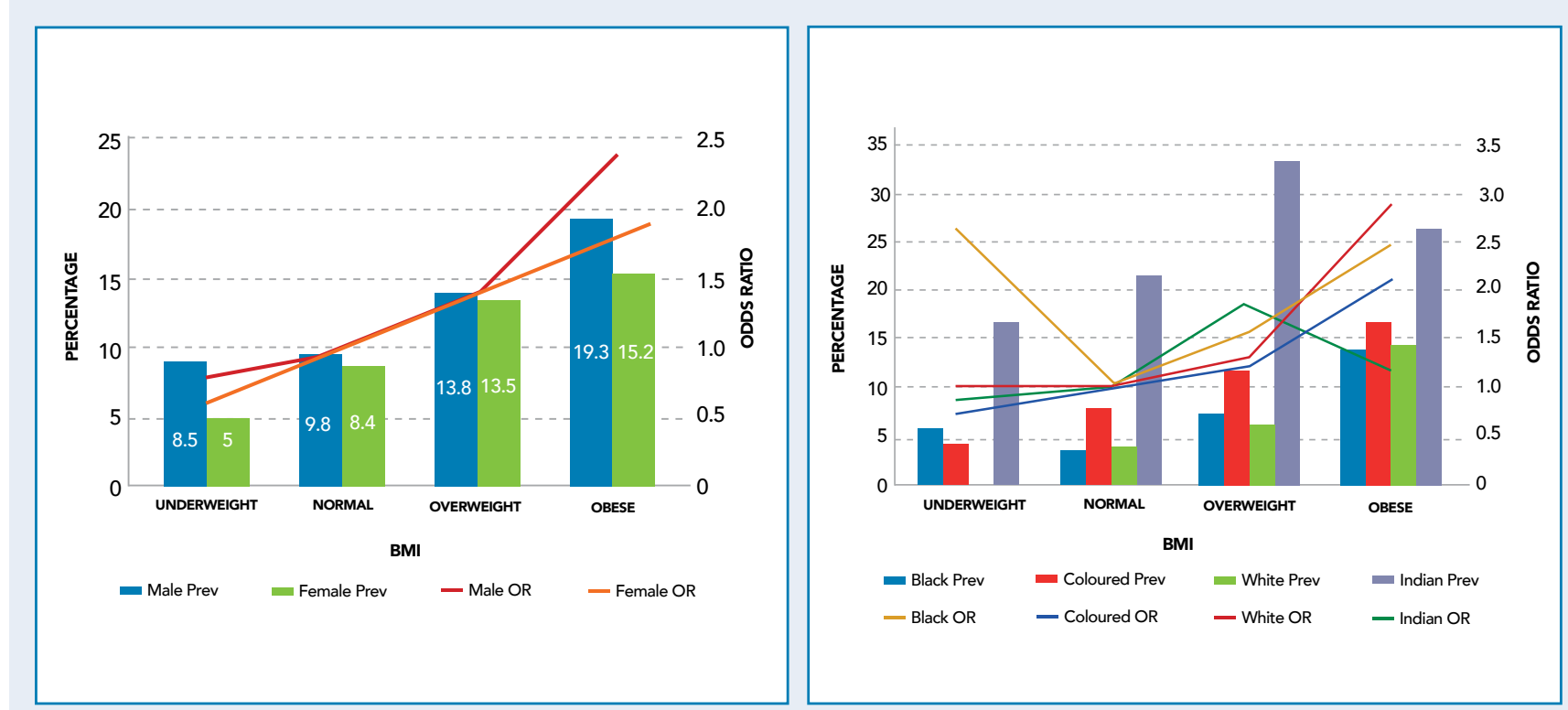

Figure 1: Prevalence and odds of diabetes by BMI category and gender

Figure 4: Prevalence and odds of diabetes by BMI category and population group

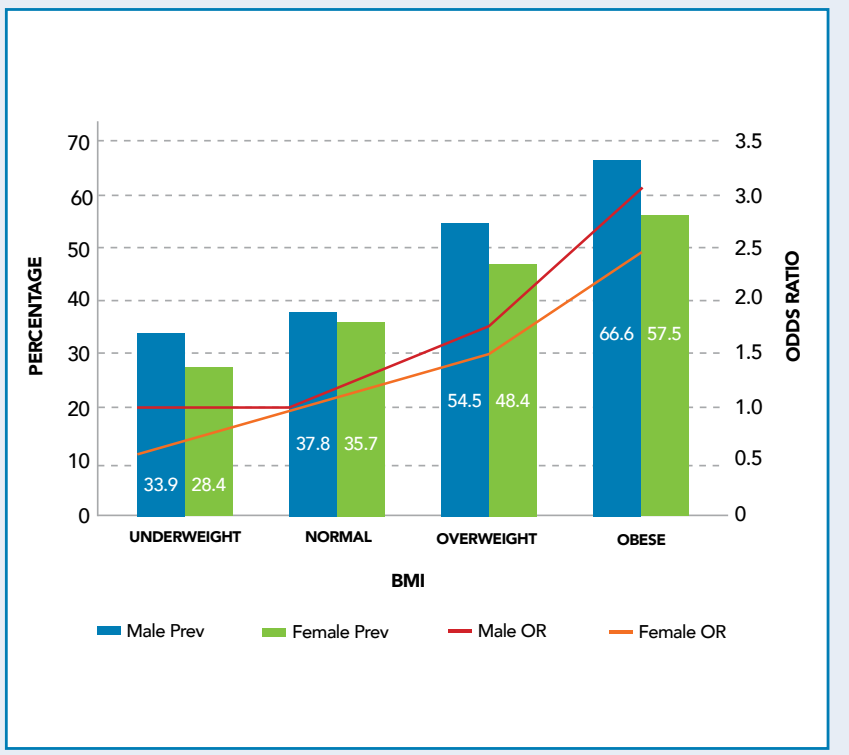

Figure 2: Prevalence and odds of hypertension by BMI category and gender

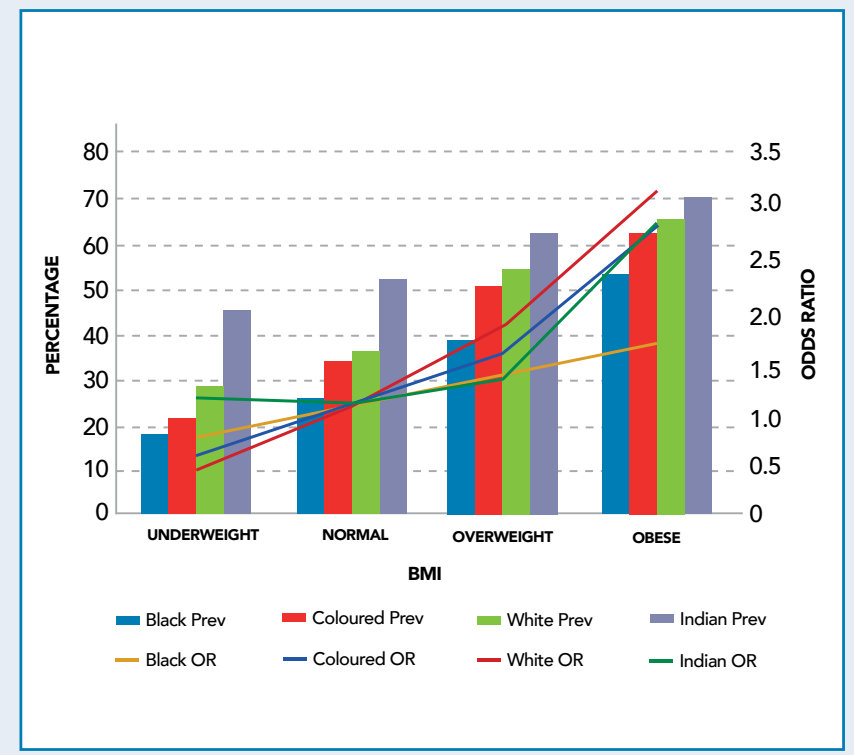

Figure 5: Prevalence and odds of hypertension by BM category and population grou

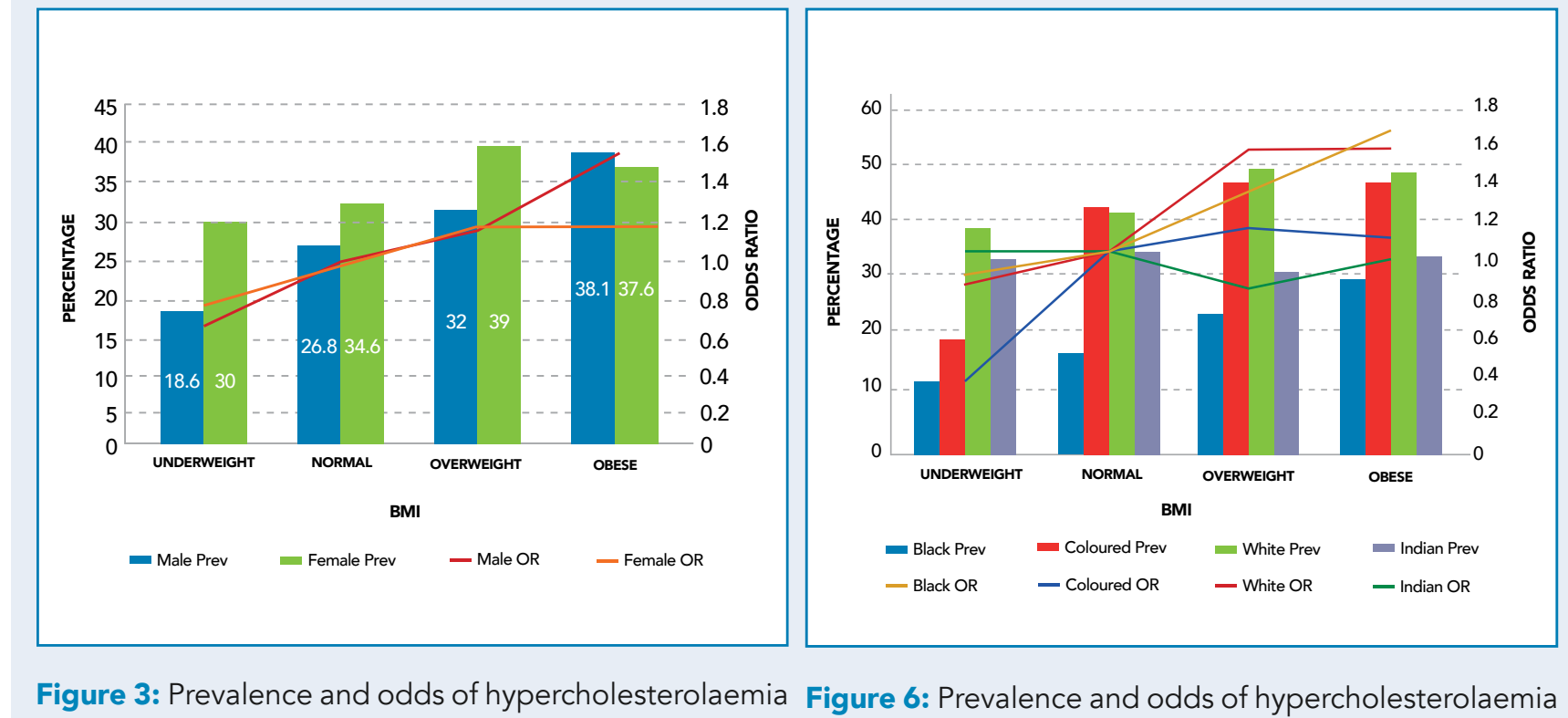

by BMI category and gender by BMI category and population group

\section{CONCLUSIONS}

Men vs. women:

Lower obesity levels but similar to higher prevalence of diabetes and hypertension $\rightarrow$ Suggests a greater susceptibility in men for these cardiometabolic abnormalities at a particular adiposity level

\section{Black population:}

Direct, but not significant, association of underweight with diabetes $\rightarrow$ ?Early life factors

\section{Indian population:}

Greater propensity for diabetes and hypertension per BMI category $\rightarrow$ Influence of other risk factors e.g. genetics 